\title{
PFC Performance Improvement of Ultra-supercritical Secondary Reheat Unit
}

\author{
Jun $\mathrm{LI}^{1,}{ }^{*}$, WeiWei $\mathrm{LI}^{2}$, XingWang $\mathrm{Hu}^{3}$, WenChuan $\mathrm{Sun}^{3}$ and Gang Kong ${ }^{1}$ \\ ${ }^{1}$ State Grid Shandong Electric Power Research Institute, Ji'nan, Shandong 250002, China \\ ${ }^{2}$ Network Center, Shandong University of Arts, Ji'nan, Shandong 250014, China \\ ${ }^{3}$ State Grid Shandong Electric Power Company, Ji'nan Shandong 250001, China
}

\begin{abstract}
Ultra-supercritical secondary reheat unit has been widely used in the world because of its advantages of large capacity, low consumption and high efficiency etc., but rapid load change ability of the turbines to be weakened which caused by its system organization, cannot meet the requirements of power grid frequency modulation. Based on the analysis of the control characteristics of ultra-supercritical oncethrough reheat unit, the primary frequency control based on feed-water flow overshoot compensation is proposed. The main steam pressure generated by the feed-water is changed to improve the primary frequency control capability. The relevant control strategy has been applied to the $1000 \mathrm{MW}$ secondary reheating unit. The results show that the technology is feasible and has high economical efficiency.
\end{abstract}

\section{Introduction}

To develop clean energy and improve the conversion efficiency of fossil energy is the current trend. Facing this trend of development, there are large changes in China's power system power structure. First, the large amount of new energy generators have worked. Second, small capacity thermal power unit due to the high power generation coal consumption, low energy efficiency gradually quit running, large capacity and high parameters of supercritical and ultra-supercritical units is promoting operation. Supercritical units are more efficient. The supercritical unit is $2 \%$ higher than the subcritical unit, and the supercritical unit is 3\% higher than the supercritical unit, which has great advantages in energy saving and emission reduction [1,2].

The state planning commission requires that the new $600 \mathrm{MW}$ and above units should adopt supercritical technology. The cost of participating in primary frequency compensation(PFC) is huge. The economy and safety of supercritical and ultra-supercritical thermal power units are often adversely affected by frequency modulation. For large-capacity and high-parameter thermal power units, the problem is more serious unit safety. Under the background that the existing bearing capacity of generator set has not been greatly improved, the main steam pressure and temperature of the unit are greatly raised, so, the thermal stress caused by the boiler steam pressure fluctuation becomes more prominent. In recent years, many power plants in China have repeatedly suffered serious accidents such as the explosion of the boiler tube [3-5]. This not only brings huge economic losses to the power plant, but also causes large disturbance to the power system due to the sudden shutdown of large-capacity generating units. Some units in order to run safely, the main steam pressure and temperature have to be lowered to a sub-critical level to prevent the boiler accident, but after the parameter is reduced, the meaning of supercritical and ultrasupercritical units have been lost. Therefore, how to make the thermal power unit fully participate in frequency modulation and reduce the cost of frequency modulation by means of technical means is a difficult problem.

\section{Features of Secondary Reheat Ultra- supercritical Unit}

Supercritical and ultra-supercritical boilers are composed of heated pipes without steam drum. Main steam valve control the steam turbine power, at the same time, in turn affect the once-through boiler outlet resistance characteristics[6]. Because of the lack of the steam drum cushion, dynamic characteristics which influenced by main steam valve opening is far greater than the drum boiler, therefore, the characteristics of once-through boiler and steam drum boiler is completely different. For example, when the load of the turbine increases, the turbine power regulation system drives the main steam valve to open, the steam flowing into the turbine increasing, the large lag and inertia of boiler cannot quickly generate enough steam to match the turbine, so the main steam pressure drop, weaken the regulator flow increase. Because of the power balance, the turbine power regulation system will continue to function, further opening the valve to get more steam, which will

\footnotetext{
* Corresponding author: lijunsepco@163.com
} 
make the main steam pressure continue to deteriorate, such a vicious circle.

Drum boilers have steam drum, even if the turbine flow greater changes, the changes of main steam pressure is not too large. Due to the relatively small regenerative heat of the boiler, the once-through boiler is more sensitive to the disturbance, which makes the coupling between the turbine and the boiler serious. As a result, the pressure of the main steam changes greatly, which not only reduces the control quality but also increases the risk of the once-through boiler operation. Therefore, under the traditional strategy of PFC, fluctuation of main steam pressure and temperature caused by random load changes will have a very adverse effect on the operation of supercritical and ultrasupercritical units.

To meet the requirements of energy saving and environmental protection, ultra-supercritical secondary reheat boiler has a secondary reheat tower structure, which is reheated once more than the conventional unit. With the heating surface increased, energy storage is greatly increased. Due to the secondary reheat unit has one extra high pressure cylinder than the conventional unit, the work ratio of the turbine is $19.8 \%$ of the ultrahigh pressure cylinder, $21 \%$ of the high pressure cylinder and $59.2 \%$ of the intermediate and low pressure cylinder. The conventional primary reheat turbine basic work is $33.3 \%$ of high pressure cylinder , $33.3 \%$ of intermediate pressure cylinder and $33.3 \%$ of low pressure cylinder. Compared with primary reheat unit, the load by the high pressure cylinder of secondary reheat unit accounts for nearly half of it, which reduces the throttling loss of the turbine to a certain extent and improve the turbine operating efficiency, but also cause the rapid load change ability of turbine to poor.

\section{Control Characteristics of Secondary Reheat Ultra-supercritical Unit}

The emphasis of traditional machine-network coordination is the interaction between the grid and the generator, but often neglect the safety and dynamic characteristics of the boiler. Under the background of serious coupling between the once-through boiler and turbine and the low heat storage of the once-through boiler, the safety and life issues need to be refocused on. The traditional control of machine-network coordination means that when the external load changes, the power change command is sent to the boiler and turbine control system at the same time, and the valve opening and the boiler are adjusted synchronously. The core idea of the control is to improve the response speed of the unit to the load change of the power grid, and not fully consider the pressure fluctuation of the boiler.

In other words, the traditional machine-network coordination and machine-boiler coordination control focus on the turbine and power grid, PFC loop only reflects the negative feedback control strategy for power grid frequency, does not consider the impact on the boiler, thus there is a big security risk. Considering the characteristics of supercritical and ultra-supercritical units, the problem of PFC will develop into a coordinated control problem of boiler, machine and network. The control method that takes into account the economy, safety and operational safety of the unit is considered. So that the supercritical units not only fully participate in the power system frequency control, but also greatly reduces the frequency modulation parameters caused by the huge volatility, achieve the goal of network and source win-win.

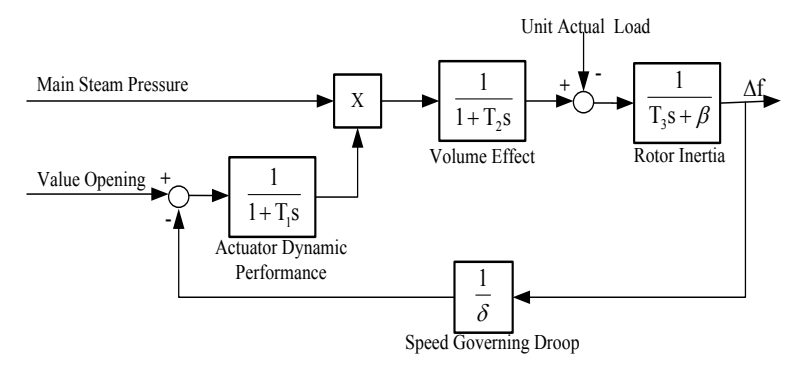

Fig. 1. PFC Mathematical Model of the Turbine

PFC is the unit near the working point of active power of small-scale adjustment, so for the primary frequency control analysis of turbine model is linear model, so the dynamic properties can be expressed by the transfer function. The coupling of the turbine and the once-through boiler is main steam flow regulating valve, which is the main steam valve opening and main steam pressure. Therefore, the turbine model should include the main steam flow and the main steam pressure. The dynamic characteristics of PFC is need to consider the actuator dynamics, high-pressure cylinder steam volume and rotor inertia. According to the input and output relationship of each component, the above links is the first-order inertia link which is shown in Fig.1.

According to the principle of gas flowing through the main steam valve, the main steam flow is related to the main steam pressure and the opening degree of main steam valve, which is proportional to the product.

$$
\mathrm{G}_{\mathrm{s}}=k P_{s} S_{v}
$$

In the formula, $\mathrm{G}_{\mathrm{s}}$ is the main steam flow, $k$ is constant coefficient, $P_{s}$ is the main steam pressure, $S_{v}$ is the opening degree of main steam valve.

In order to make the turbine actual power tracking the given power, the power feedback is need to be sent to the control loop. Regardless of the main steam pressure fluctuations, the schematic diagram shown in Fig.2. On the basis of the pure speed regulation, the electric power output from the generator is measured, and then fed back to the input, which is the valve control signal of the turbine after the sum of the given power and the primary frequency.

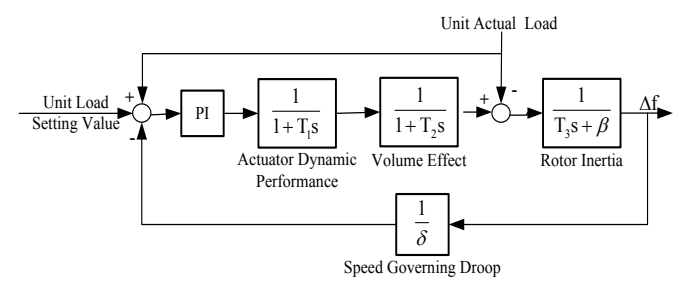

Fig.2. Power-frequency Adjustment Mode Principle 


\section{Optimization Design and Result}

The grid-connected power plant must be equipped with one frequency modulation function, and the primary frequency modulation investment/withdrawal signals should be connected to the power dispatching agencies. The artificial dead zone, the rate of change of the speed regulation system and the maximum adjustment load limit of the primary frequency regulation, and the speed control system of delay rate, response speed and so on should meet the requirements of the primary frequency regulation technology management of the regional grid[7,8]..Units running in the grid must be put into primary frequency modulation function, when the grid frequency fluctuations should automatically participate in frequency modulation, and the grid power plant must not withdraw from the unit's frequency modulation function.

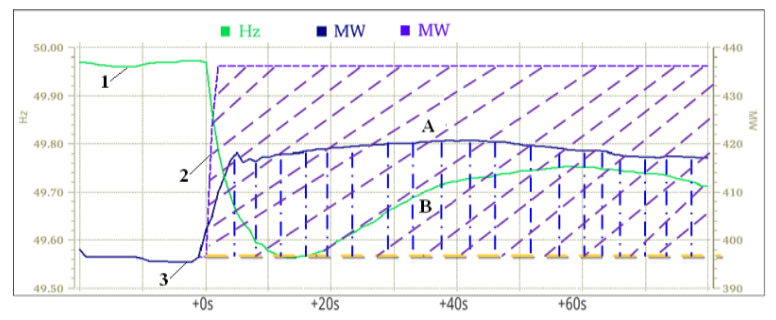

Fig.3. Schematic of PFC Assessment Criteria

The unit's load response when grid frequency in the fall is shown in Fig.3. Among them, 1 is the grid frequency, 2 is the standard load output, and 3 is the actual load output. The shadow area $\mathrm{A}$ is the integral area that the standard load output minus the initial load output on the assessment time. The shadow area B is the integral area that the actual load output minus the initial load output on the assessment time.

$\mathrm{P}_{0}$ is the unit actual load at $\mathrm{t}_{0}$ moment. $\operatorname{Pr}(\mathrm{t})$ is the unit actual load at different time. $\operatorname{Ps}(\mathrm{t})$ is the unit standard load at different time. According to the Chinese primary frequency modulation standards. The value of $\eta$ needs to exceed $80 \%$ to meet the standard requirements. Because of the different heat storage capacity, the action time of PFC to different types of thermal power unit is 0.5 to 2 minutes inequality. PFC is adjusted by the control methods according to differ characteristics. So, it is possible to meet the standard requirements by increasing the amount of load in the later period.

\subsection{Method Design}

According to 'Guide of primary frequency control test and performance acceptance for thermal power generation units' and other technical standards, unit's speed governor droop is no more than $5 \%$, rated grid frequency is $50 \mathrm{~Hz}$, dead zone of PFC is $\pm 0.033 \mathrm{~Hz}$.

When the grid frequency deviation value does not exceeded the setting range or the unit regulating command is not fully opened, the unit uses the regenerative heat and the regulating valve to adjust the unit load. When the grid frequency deviation exceeds the setting range and the regulating command is fully open, the feed-water flow overshoot compensation can be used. The secondary reheat ultra-supercritical cannot satisfy the requirement of primary frequency load modulation when the frequency difference of the power grid is large In actual operation, if the unit's water flow changes within a certain range in a certain period of time, it will not affect the steam temperature of the unit, but will cause the main steam to change. However, the change of the main steam pressure will have obvious effect on unit power, that is, the main steam pressure can changed by adjusting the water flow.

As a feasible implementation, when the power grid frequency deviation exceeds the set range, firstly, if the unit regulating command is more than $99 \%$, namely the

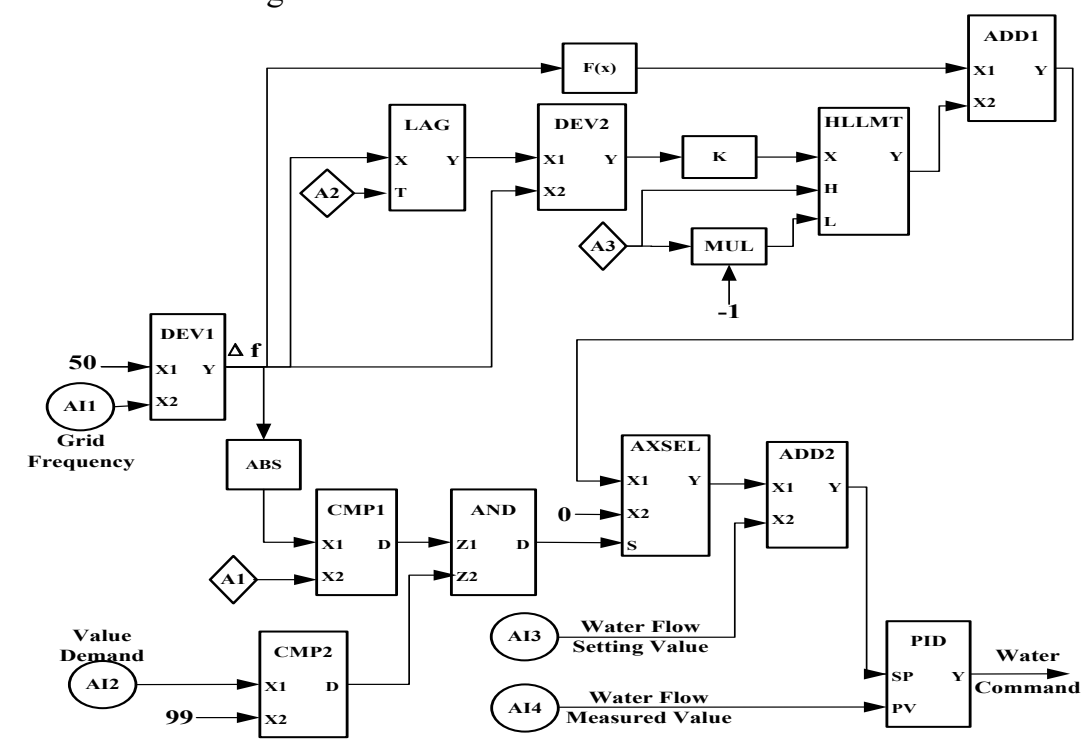

Fig.4. Schematic Diagram of PFC Optimal Control System Based on Feed-water Flow Overshoot Compensation 
unit's value is fully open, the system will be according to the power grid frequency deviation value calculated by the superposition of feed-water flow overshoot offsets to the original, generate a new feed-water flow value. Secondly, if the unit regulating command is not greater than $99 \%$, the unit shall be deemed to be tone still has to adjust allowance, use tone to adjust the opening value, namely the normal regulation of feed-water flow set point to keep the original.

As shown in Fig.4, DEV is the subtracter module, $\mathrm{F}(\mathrm{x})$ is a dead zone nonlinear function, LAG is a delay module, HLLMT is the high and low limit limiting module, AXSEL is the analog selector, $\mathrm{A}$ is the analog generator, CMP is the comparator module. Through the value of frequency modulation measurement, it is effective to use the heat storage and feed-water supply to ensure the frequency modulation capability of the unit.

\subsection{Application Effect}

Take one 1000MW ultra-supercritical secondary reheat unit as an example, host parameters were $31 \mathrm{MPa} / 600^{\circ} \mathrm{C}$ $1620^{\circ} \mathrm{C} / 620^{\circ} \mathrm{C}$, the parameter is in the international leading level. Considering the heat storage and pressure changes, set the grid frequency deviation value 0.1 in $\mathrm{A} 1$, and the lag time set in $\mathrm{A} 2$ is $10 \mathrm{~s}$, the high and low limit limiting set in A3 is 50.According to the relationship between the change of feed-water flow and power change,

$$
\Delta t / H=3 \times \Delta M W+50
$$

that is, multiply the primary frequency variation by 3 times and add 50 to get the value of the change of feedwater flow, that is, the total ADD1 output is this value. The assessment indicators of before and after the technical transformation is shown in Table1.

Table 1.Monthly Statistics of Grid Frequency Assessment

\begin{tabular}{|c|c|c|c|}
\hline Date & $\begin{array}{c}\text { Electricity } \\
\text { Assessment } \\
\text { (MWh) }\end{array}$ & Date & $\begin{array}{c}\text { Electricity } \\
\text { Assessment } \\
\text { (MWh) }\end{array}$ \\
\hline $2016-1$ & 500.30 & $2017-1$ & 16.02 \\
\hline $2016-2$ & 155.16 & $2017-2$ & 137.25 \\
\hline $2016-3$ & 529.30 & $2017-3$ & 18.28 \\
\hline $2016-4$ & 669.30 & $2017-4$ & 0.34 \\
\hline $2016-5$ & 878.00 & $2017-5$ & 31.72 \\
\hline $2016-6$ & 675.40 & $2017-6$ & 67.81 \\
\hline $2016-7$ & 684.09 & $2017-7$ & 273.02 \\
\hline $2016-8$ & 512.20 & $2017-8$ & 255.83 \\
\hline $2016-9$ & 189.75 & $2017-9$ & 57.56 \\
\hline Total & 4793.50 & & 857.83 \\
\hline
\end{tabular}

Comparing between January to September of 2016 and 2017, the grid assessment of PFC are 4793.50MWh and67.81MWh respectively, which improve the performance by more than $80 \%$. According to the electricity price 0.3924 yuan/kWh calculation, 1.54 million yuan can be obtained. The economic benefits were significant.

\section{Conclusion}

By analyzing the control characteristics of the thermal power units, especially the ultra-supercritical secondary reheat units, combined with the frequency control requirements of the power grid with large-scale power gaps, the performance improvement technique of PFC was proposed. Under the premise of ensure the stable operation, by changing the feed-water flow to further improve the quality of PFC, the method can improve unit's dynamic adjustment ability of power system frequency, and ensure its stable operation at the same time. In the smart grid environment, it is of great significance to improve the coordination ability of all kinds of units, to improve the stable operation of power grids.

\section{References}

1. G. Nowak, A. Rusin. Shape and operation optimization of a supercritical steam turbine rotor[J]. Energy Conversion and Management, 2013,74:417-425.

2. Dai Yiping, Zhao Ting, Tian Yunfeng. Research on the primary frequency control characteristics of generators in power system[J]. Second IEEE Conference on Industrial Electronics and Applications, 2007, 569-574.

3. Mo Yaowei. Research of pipe explosion of 1000MW ultra-supercritical unit boilers[J]. East China Electric Power, 2008,36(2):16-22.

4. AntonioVisioli. A new design for a PID plus feedforward controller[J]. Journal of Process Control, 2004,14:457-463.

5. F.Shinskey. Process Control Systems Application Design Adjustment[J]. McGraw-Hill, New York, 1996.

6. Huang, H.P. \& Jeng, J.C. Monitoring and assessment of control performance for single loop systems[J]. Ind. Eng. Chem. Res., 2002, 41:12971309.

7. Yu Daren, Guo Yufeng, Xu Jiyu. The primary frequency regulation stability of parallel turbogenerators[J]. Proceedings of the CSEE, 2000, 20(9):59-63.

8. Li Duanchao, Chen Shi, Chen Zhongyuan. Realtime measurement and reward method of the efficiency of generator unit primary frequency regulation[J]. Automation of Electric Power Systems, 2004, 28(2): 70-72.

\footnotetext{
* Corresponding author: lijunsepco@163.com
} 